\title{
A COMPARISON OF MOOD STRUCTURES IN TWO TV TALK SHOWS WITH GUESTS OF DIFFERENT SOCIAL STATUS
}

\author{
Ae Mon Kyaw, Xin Zhiying, Vincent Mbahawa Chefor \\ Xiamen University, Xiamen, China \\ E-mail: kyawaemon@gmail.com
}

Received: 22 October 2019

Accepted: 09 April 2020

\begin{abstract}
Language cannot be separated from the social context and culture. In everyday communication, people act and react differently depending on interactants, topics involved, and means of communication. This study, therefore, analyses two Talk Shows with guests of different power statusEllen with Vice President Joe Biden and Ellen with Special Education teacher Jenna Albi. The analysis is carried out using Halliday's Mood analysis framework, as revised by Matthiessen (2014) and Eggin (2004). The present study compares Ellen's use of Mood structures and their functions in the interaction with different social beings. It reveals that in the talk with the Vice President, Ellen uses questions most (28.37\%), followed by statements (20\%) while in the talk with the Special Education teacher, Ellen prioritizes statements $(43 \%)$ over questions (14\%). On the other hand, she does not enjoy any Commands (0\%) in the talk with the Vice President but does so with the teacher (18\%). It turns out that, unlike in Fairclough's (2001) finding, participants with high power status tend to answer questions rather than asking questions.
\end{abstract}

Keywords: Systemic Functional Linguistics, Mood analysis, Power, Ellen Talk Show, Speech function

\section{Introduction}

What is the function of meaning in our everyday life? Halliday (1985) encapsulated meaning in his three metafunctions of language, namely, the experiential meaning, the interpersonal meaning, and the textual meaning. Experiential meaning is interpreting language as an experience, interpersonal meaning refers to language as an exchange and textual meaning refers to language as a message.

Talking about the context of situation, Halliday (1985) also introduced three conceptual terms "Field, Tenor, and Mode". Field is the subject that the participants are talking about; Tenor is the relationship between the participants in the conversation; and Mode is the medium that participants use to communicate with each other.

The corpus of this study is made up of two recordings of the "Ellen Talk Show", in which there is a great deal of interactions between participants. Ellen DeGeneres is a celebrity in the United States who has interviewed several people with different social statuses, including former Presidents George Bush, Barack Obama, and movie star Jackie Chan. With the aim to analyze the semantics and lexico-grammatical structures of the exchanges between different social beings, the present study choose to examine two Talk Shows- the interaction between Ellen and Vice President, Joe Biden and the one between Ellen and Special Education teacher 
A Comparison of Mood Structures in Two TV Talk Shows with Guests of Different Social Status, Ae Mon Kyaw, Xin Zhiying, Vincent Mbahawa Chefor

Jenna Albi. One of Halliday's metafunctions, the interpersonal metafunction, with a special focus on the Mood analysis, is employed to interpret and compare the interaction between Ellen and the Vice President and Ellen and the Special Education teacher.

A few researches on Mood analysis in interviews have been conducted in the past, focusing on the frequency of Mood structures, the types of Mood structures mostly enjoyed by various participants and their reasons.

Mood analysis of Doctor-patient relations, religious speeches, poems, teacher talks, interviews, etc. have been conducted. However, a few studies have been conducted on the comparison of Mood structures in different Talk Shows. The present study will attempt to fill this gap by focusing on the main host, Ellen, talking to two guests with different social status - Joe Biden, US Vice President and a Jenna Albi, Special Eduction teacher.

Ebi Yeibo (2011) from Niger Delta University conducted a research on "A discourseStylistic Analysis of Mood Structures in Selected Poem of J.P. Clark-Bekederemo". The discourse is analyzed with Halliday's Systemic Functional Linguistics. The study related the Mood structures with the social contexts and discovered the types of Mood structures enjoyed by the participants.

Nguyen Thanh Nga (2017) from Vietnam Military Medical University studied Mood structures used in the conversation between two different social statuses. In her paper titled "DoctorPatient power relation: A Systemic Functional Analysis of a Doctor-Patient Consultation", she discovered that the doctor had more power than the patient.

In 2015, three Pakistanis, Mehwish Noor, Moazzam Ali, Fakharh Muhabat and Bahram Kazemian from Iran collaboratively published a research on Mood analysis in the International Journal of Language and Linguistics. The research titled "Systemic Functional Linguistics Mood Analysis of the Last Address of the Holy Prophet (PBUH)" analyzed the religious speech of the Holy Prophet, highlighting the frequency of use of different Mood types and explaining their various speech functions. After finding out that in the analyzed 56-clauses religious speech, 32 were declarative, 22 imperative and one interrogative, they concluded that declarative forms were mostly used in order to reveal higher power status in the interaction.

Adinoto, T. K. (2012) from Nigeria also conducted a "Mood Analysis on Interview Between Oprah Winfrey and Ricky Martin on the Oprah Winfrey Show". Analyzing the interview between two figures, the article examined the frequency of the Mood structures and found out that the declarative Mood type was predominant. In addition, the interviewee, Ricky Martin, mostly used declaratives to pass on information.

Fikri, Z., Padmadewi, N. N., \& Suarnajaya, I. W. (2014) carried out a "Mood Structure Analysis of Teacher Talk in EFL Classroom: A Discourse Study Based on Systemic Functional Linguistic Theory". They sought to know who, in the EFL classroom, made the most use of speech functions, and what the different realizations of these functions were. It stood out that speech functions were mostly used by teachers. In other words, power status and frequency of usage of speech functions are claimed to be related in this paper. Furthermore, there is also a relationship between the gender and the choice of Mood structures; male teachers used more information and command structures among others. The study assumed that culture could be one of the reasons of differences in the use of Mood structures.

Previous research mostly dealt with the frequency of Mood structures and the types and functions of structures used. Some other research related the realization of Mood structures with gender; male teachers used more speech function than female teachers. In addition, they underscore the fact that persons with higher power status use more declarative structures, as documented in Bankole and Ayoola (2005), Mehwish Noor, Moazzam Ali, Fakharh 
Muhabat and Bahram Kazemian (2015). However, there has been no research which compares the same participant interacting with two persons of different social statuses. Therefore, the present study will focus on the talk show host, Ellen, as main participant, and will determine the types of Mood structures she uses and the types of speech functions realized by these structures.

\section{Research Questions}

(1) Is there any difference in the use of Ellen's mood structure when communicating with US Vice President, Joe Biden, and the Special Education teacher Jenna Albi?

(2) Is there any difference in the use of Ellen's speech functions when communicating with US Vice President, Joe Biden, and the Special Education teacher Jenna Albi?

\section{Literature Review}

\subsection{Mood Analysis}

Systemic functional linguist, Halliday (1985), sees that language has three functions: language as an experience, language as an exchange and language as a message. They are technically called ideational meaning, interpersonal meaning, and textual meaning respectively. Mood analysis is the grammatical realization of interpersonal meaning. There are three types of Mood structures: declarative, imperative and interrogative. In determining the type of Mood structures, some constituents of the Mood are necessary to identify: Subject, Finite, and Predicator.

What is Subject? Halliday and Matthiessen (2004: 117) state that subject is "something by reference to which the proposition can be affirmed or denied". In fact, subject is "responsible for the functioning of the clause as an interactive event". It can determine the "success or failure of the proposition". It can be identified with the help of tag. For example, She is a Teacher, isn't she? In this example, she is a subject because it can be tagged.

What is Finite? "The Finite element, as its name implies, has the function of making the proposition finite." Halliday and Matthiessen (2004:115). It can also be identified with the help of a tag. For example, She is a Teacher, isn't she? In this example, isn't is a finite because it's a verb used in a tag.

According to Eggins (2004: 177), the mood structures can be identified with the order of Subject and Finite.

Declarative Mood is Subject + Finite $+\ldots . .$. .

For example, She (Subject) + is (Finite) + a Teacher.

Polar Interrogative Mood is Finite + Subject $+\ldots . .$.

For example, Are (Finite) + you (Subject) + a Teacher?

In Wh- Interrogative Mood, if the Wh-element is the Subject, Subject + Finite and otherwise Finite+ Subject.

+ do?

For example, Who (Subject) + did (Finite) + it? And What + did (Finite) + you (Subject)

Imperative Mood can be in four structures.

(i) Finite + Subject.

e.g Don't (Finite) + you (Subject) + go there.

(ii) Only Finite as a Mood element.

e.g Do (Finite) + come here.

(iii) Only Subject as a Mood element. 
A Comparison of Mood Structures in Two TV Talk Shows with Guests of Different Social Status, Ae Mon Kyaw, Xin Zhiying, Vincent Mbahawa Chefor

e.g Let's ( Subject) + go.

(iv) Without Finite and Subject, only Predicator

e.g Study (Predicator) + your lesson.

\subsection{Minor Clauses}

A minor clause does not have Subject and Finite. It has 5 functions: Exclamations, Calls, Greetings, Alarms, and Backchannels or Continuatives. (Halliday and Matthiessen, 2014:196). Examples of minor clauses functioning as exclamations include Wow!, Yuck!, Aha!, Bullshit!, Terrific!. Some exclamations are clauses such as What a nice view!, How pretty the girl is!. Calls include addressing someone or something whether it is animate or inanimate. For instance, Christ, Professor, You there!. Greeting-functioning minor clauses are Hello! Good Morning!, Welcome!, etc. Greetings also cover wishes such as Congratulations! Happy New Year!, Merry Christmas!. Minor clauses which function as alarms are such warnings as Look out!, Quick!, Help! Fire!, etc. Backchannels include the fillers, which function is to keep the conversation going. For example, Yeah!, Okay, Uh-huh, $m m$, etc.

\subsection{Ellipisis}

There are two types of Ellipsis: Anaphoric ellipsis and Exophoric ellipsis. Anaphoric ellipsis usually occurs in a response to the previous message. For example, - Where are you going? - to the cinema. Here, Subject and Finite are omitted. Only "to the cinema" is provided. Exophoric ellipsis usually occurs when the situation or context is obvious. In other words, the speaker and the listener(s) know what the subject and Finite are. For example, Hungry? To the park? In this example, the listener already knows who the speaker is talking about. Therefore, exophoric ellipsis is used when the 'subject' is clear to listeners.

\section{Research Method}

With the aim to find out the relation between Mood analysis and power status, the Talk Show is selected as a material where a great deal of interactions takes place. The Ellen Talk Show, under consideration in this paper, has played host to a number of guests from different social backgrounds, including politicians, celebrities, teachers, musicians, etc. In this Talk Show, comparison is made between the mood structures employed by Ellen in her interaction with two different social figures; US Vice President, Joe Biden, and Special Education teacher Jenna Albi. In the Talk Shows, some interaction clauses with other peoplethe audience- are omitted.

The Ellen Talk Shows are first transcribed from You-Tube video. Then the materials are analyzed using Systemic Functional Linguistics by Halliday (Eggins, 2004). To answer the research question, the mood structures of the conversations are first identified as Declarative, Imperative, Interrogative or Minor Clauses. Secondly, the mood structures preferred by Ellen in both Talk Shows are extracted and their differences are highlighted. Thirdly, the speech functions of the clauses are determined as statement, questions, etc. Finally, the differences in Ellen's use of speech functions in both Talk Shows are compared. Therefore, the present study is a mixed method- both quantitative and qualitative study.

\section{Findings and Discussion}

Using Halliday's Systemic Functional Linguistics (1985), the present study analyzed two Ellen Talk Shows: the Talk Show with a US Vice President and the Talk Show with a Special Eduction teacher. Then, the mood structures and functions of each Talk Show were explored, 
followed by the comparison between the mood structures and functions by Ellen in the two different Talk Shows. The following is the summary of the mood structures found in the Talk Shows.

Table 1. Frequency of Total Mood structures found in both Talk Shows

\begin{tabular}{|l|l|l|l|l|}
\hline Mood Structures & $\begin{array}{l}\text { Total No. in the } \\
\text { talk with the } \\
\text { Vice President }\end{array}$ & Total 100\% & $\begin{array}{l}\text { Total No. in } \\
\text { the talk with } \\
\text { the Teacher }\end{array}$ & Total 100\% \\
\hline D & 67 & $61 \%$ & 89 & $77 \%$ \\
\hline Ellipitical D & 4 & $4 \%$ & 8 & $7 \%$ \\
\hline Abandoned D & 2 & $2 \%$ & 0 & $0 \%$ \\
\hline Interrogative & 14 & $13 \%$ & 2 & $2 \%$ \\
\hline $\begin{array}{l}\text { Modul } \\
\text { Interrogative }\end{array}$ & 3 & $3 \%$ & 0 & $0 \%$ \\
\hline Imperative & 5 & $5 \%$ & 6 & $5 \%$ \\
\hline Minor Clause & 15 & $14 \%$ & 10 & $9 \%$ \\
\hline Total & 110 & $100 \%$ & 115 & $100 \%$ \\
\hline
\end{tabular}

As shown in Table 1, there are altogether 110 clauses in the Talk Show with the US Vice President and 115 clauses in the Talk with the Special Education teacher. There is not much difference in the number of clauses between the two Talk Shows. Moreover, to make the data more valid, the Talk Shows are chosen with a little difference in the Talk Show length - both of them last 9 -10 minutes. The table shows that the most frequently used mood structure in both talk shows is Declarative - $(67 \%)$ in the talk with the US Vice President and (89\%) in the talk with the Special Education teacher. Most of the Declaratives are used for statement in the Talk Shows, which is in line with Eggins' (2004) line of thought. However, the marked Declaratives are for the functions of offer, acknowledgement, question, and command. For example,

Joe Biden : By the way, I got a gift for you. (Offer)

Joe Biden : : got a real gift, (Offer)

Joe Biden : So this is for your mom. (Offer)

Ellen

: It's amazing what you are doing. (Acknowledgement)

Ellen

: That's so good. (Acknowledgement)

Ellen

: That's amazing. (Acknowledgement)

Ellen

: You can't be- you have to rest. (Command)

Ellen : : You have to be rested to go (Command)

Ellen $\quad:$ and help these kids that you're doing. (Command)

Ellen : So you have always wanted to be a teacher? (Question)

Ellen : So and the biggest issue with the school is what? (Question)

Joe Biden : By the way, you know what my wife said to me? (Question)

On the other hand, only two Modulative Interrogatives are employed by the participants to make Offers; "Would you sit down?" and "May I do this?". The unmarked mood type for making an offer is Modulative Interrogatives (Eggins, 2004). However, the result of this research shows that speakers more frequently used Declaratives to make offers.

To answer the research question - any difference in Ellen's use of Mood structures in the two Talk Shows, only Ellen's Mood types are extracted and compared. 
A Comparison of Mood Structures in Two TV Talk Shows with Guests of Different Social Status, Ae Mon Kyaw, Xin Zhiying, Vincent Mbahawa Chefor

\section{Chart 1.Comparison of Ellen's Mood structures in two Talk Shows}

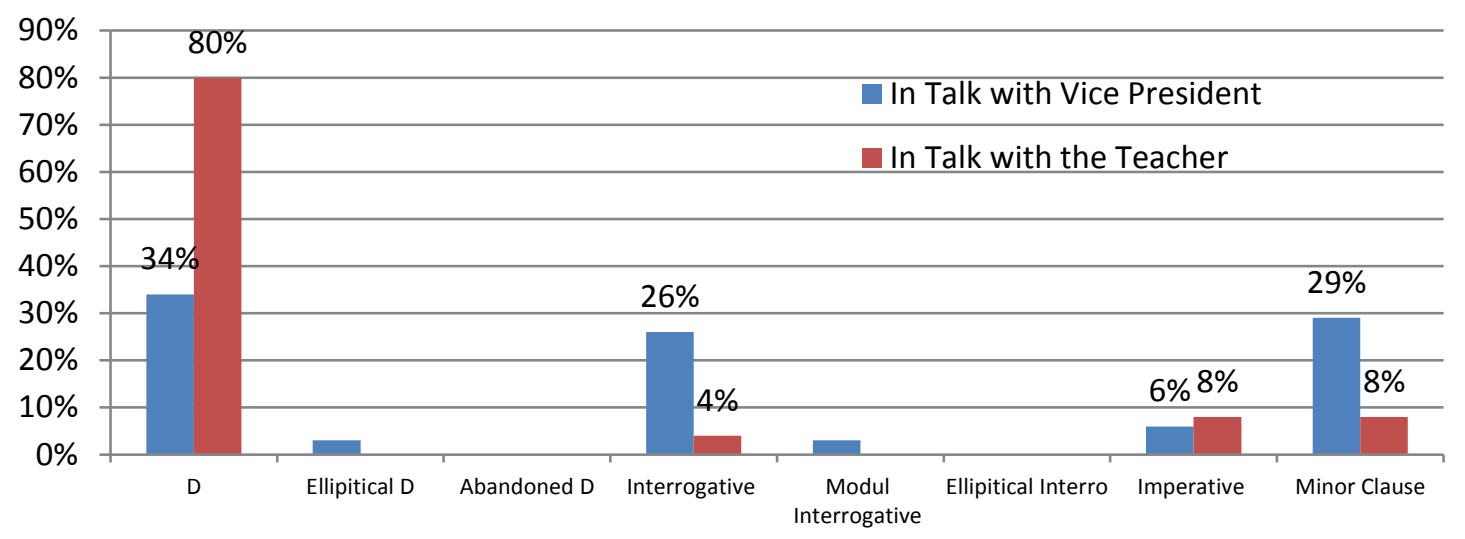

From the first glance at Chart 1, it can be seen that Ellen uses more Declaratives than Modulative Interrogatives, Imperatives and Minor Clauses. This is due to the medium of interaction, that is, the Talk Show, where participants are supposed to exchange information. Noticeably, in the talk with the US Vice President, Ellen used 29\% of Minor clauses, which is almost the same as $34 \%$ of Declaratives. This is because Ellen said greetings, employed backchanneling with the participants, especially with the US Vice President.

By comparing Ellen's use of mood type in both Talk Shows, it is noted that Ellen uses more Declaratives with the Special Education teacher (80\%) than with the US Vice President (34\%). In other words, Ellen gave more information to the teacher than to the Vice President, with whom she, rather, gave more compliance, greeting and backchanneling (29\%), thereby revealing unequal power status.

Surprisingly, Ellen used more Interrogatives with the Vice President (26\%) than with the Teacher (4\%). All the Interrogatives that Ellen used function as questions in order to request for information.

The use of the Imperative "Thank you" in the talk with the US Vice President is just to express acknowledgement, while the same usage of the Imperative in the talk with the teacher"Come on down"; "Tell me about most of the kids there" is to pass a Command.

Table 2. Frequency of Total Speech Functions found in both Talk Shows

\begin{tabular}{|l|l|l|l|l|}
\hline Function & $\begin{array}{l}\text { Total No. in the } \\
\text { talk with the Vice } \\
\text { President }\end{array}$ & Total 100\% & $\begin{array}{l}\text { Total No. in the } \\
\text { talk with the } \\
\text { Teacher }\end{array}$ & Total 100\% \\
\hline Statement & 48 & $43.64 \%$ & 66 & $57.39 \%$ \\
\hline Question & 18 & $16.36 \%$ & 7 & $6.09 \%$ \\
\hline Command & 6 & $5.45 \%$ & 9 & $7.83 \%$ \\
\hline Offer & 11 & $10 \%$ & 3 & $2.61 \%$ \\
\hline Answer & 3 & $2.73 \%$ & 8 & $6.96 \%$ \\
\hline Acknowledgement & 4 & $3.64 \%$ & 11 & $9.57 \%$ \\
\hline Accept & 5 & $4.55 \%$ & 1 & $0.87 \%$ \\
\hline Compliance & 1 & $0.91 \%$ & 2 & $1.74 \%$ \\
\hline Disclaimer & 3 & $2.73 \%$ & 0 & $0.00 \%$ \\
\hline Contradiction & 1 & $0.91 \%$ & 0 & $0.00 \%$ \\
\hline Greeting/Wish & 4 & $3.64 \%$ & 2 & $1.74 \%$ \\
\hline
\end{tabular}


Language Literacy: Journal of Linguistics, Literature and Language Teaching

Volume 4, Number 1, pp:38-46, June 2020

e-ISSN: 2580-9962 I p-ISSN: 2580-8672

DOI: $10.30743 /$ II.v4i1.1839

\begin{tabular}{|l|l|l|l|l|}
\hline Exclamatives & 1 & $0.91 \%$ & 3 & $2.61 \%$ \\
\hline Backchannel & 3 & $2.73 \%$ & 3 & $2.61 \%$ \\
\hline Call & 2 & $1.82 \%$ & 0 & $0.00 \%$ \\
\hline Total & 110 & 100 & 115 & $100.00 \%$ \\
\hline
\end{tabular}

Table 2 shows the frequency of total speech functions found in both Talk Shows. The number of clauses in the Talk Show with the US Vice President and with the Special Education teacher is 110 and 115 respectively. The table shows that the most frequently delivered function in both talks is statement- $(43.64 \%)$ in the talk with the Vice President and $(57.39 \%)$ in the talk with the teacher, which means that a large amount of information is exchanged between the participants. During the talk with the Vice President, he shared information about the Affordable Care Act, which is health insurance, and his attitude towards birthdays, etc. Likewise, in the talk with the teacher, the participants talked about the teacher's life struggles. Statement functions were used to exchange the information during both talks.

On the other hand, the responding speech functions such as Compliance $(0.91 \%)$, Contradiction (0.91\%), Exclamatives (0.91\%) are least employed by participants in the talk with the Vice President, and no Disclaimer, Call, nor Contradiction are found in the talk with the teacher. Undoubtedly, Greetings, Contradictions and Exclamatives are minor clauses and they are least common in both talks.

In order to answer the research question_ any difference in Ellen's use of speech function in both Talk Shows, only Ellen's talks are excerpted from the Talk Shows. The percentage of speech function occurrence is calculated based on her own clauses. For example, Ellen used 35 clauses in the talk with the Vice President; 7 of them are statements, representing $20 \%$ of her own talk. The comparison of the use of speech functions by Ellen in both talks can be seen in Chart 2 below.

\section{Chart 2. Comparison of Ellen's use of Speech Functions in two Talk Shows}

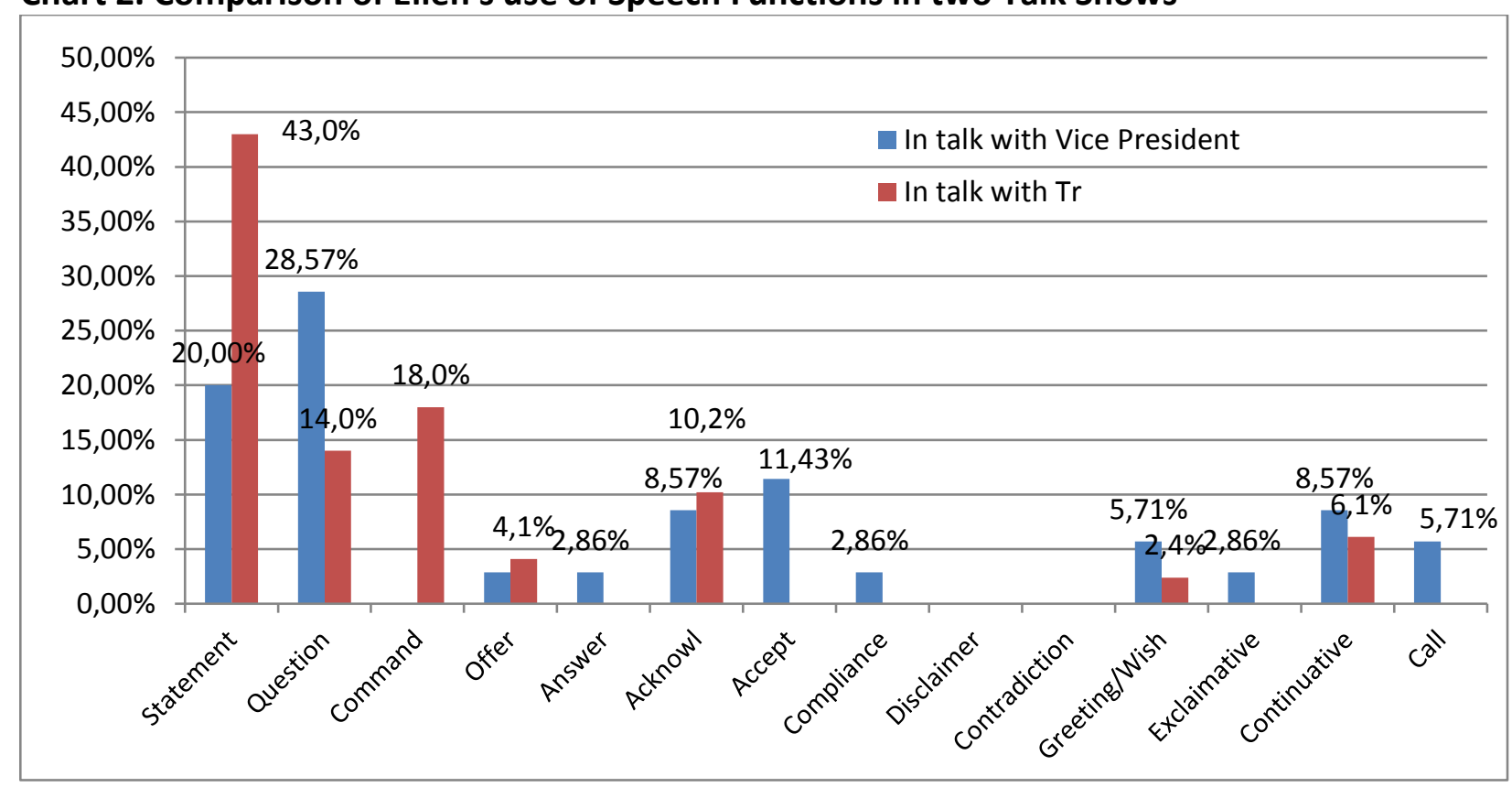

In the talk with the Vice President, it is surprisingly found that the highest frequency of speech function is question, $28.57 \%$ of her talk. She asked questions, most of the time, such 
A Comparison of Mood Structures in Two TV Talk Shows with Guests of Different Social Status, Ae Mon Kyaw, Xin Zhiying, Vincent Mbahawa Chefor

as "What are you in Los Angles for?", "What are you and Jill gonna do for Valentine's Day?", "What is happening here". This implies that, as the host of the Talk Show, Ellen initiates the conversation. This is in contradiction with Fairclough's $(2001$, p.46) findings, in which a participant with high power status, a Doctor, asked questions to low power status participants, students. Fairclough also stated that the more powerful participants control the subject position of the less powerful participant. However, it is not verified in the Talk Show that the Vice President controls the subject position of Ellen, the host of the Talk Show. This can obviously be noticed in the following exchange;

Ellen : What are you in Los Angeles for?

Vice President: Well now that you asked me.

This proves that Vice President is waiting for the host to initiate a topic.

Despite the use of questions in the Talk with the Vice President, there is no occurrence of Command in her initiating speech, Disclaimer or Contradiction in her response. The highest number of questions and the lowest number of Commands, Disclaimers and Contradictions reveal Ellen's responsibility and power status. Ellen, the one who is taking charge of the Talk Show, leads the discussion by asking questions and uses more acceptance and compliance structures to support the Vice President, instead.

In the talk with the teacher, it is found that the most frequently used function is statement (43\%). Ellen most of the time gave information to the teacher. She announced the donation to the school the teacher is working in and to the teacher, who has dedicated her own life to the unprivileged school. The least employed functions are Answer, Accept, Compliance, Disclaimer. She did not receive any offer from the teacher, unlike the Talk Show with the Vice President, in which $11.43 \%$ is Acceptance. She also didn't contradict the information that the Teacher presented.

By comparing Ellen's use of functions in two Talk Shows, it appears that Ellen gives more information to the teacher than to the Vice President. Instead, with the Vice President, Ellen asks more questions than giving information. This suggests that before the Talk Show, Ellen already had much more information about the teacher than about the Vice President. The use of Command in the Talk with the teacher (18\%) despite no Command (0\%) with the Vice President is also indicative of an unequal status encounter.

In addition, the use of acceptance in the Talk with the Vice President (11.43\%), despite no acceptance $(0 \%)$ with the teacher is also indicative of an unequal status encounter. The Vice President offers Ellen some presents while Ellen is the one who offers the teacher some money for charity.

\section{Conclusion}

In conclusion, the paper analyzed Two Talk Shows to highlight the difference in Mood type and speech function. Ellen used more Declaratives with Special Education teacher, Jenna Albi, but more Interrogatives with the US Vice President, Joe Biden. The speech functions were explored in light of the mood analysis framework from Halliday's Systemic Functional Linguistics. Concerning the exchange of information, the study surprisingly revealed that Ellen requested more information from the Vice President while she gave more information to the teacher. This finding is in contradiction with Fairclough's (2001) earlier findings, where a more powerful participant, a Doctor, kept asking questions to the student and the student only had to answer. Regarding the exchange of goods or services, it is significantly found that Ellen tends to pass on Command to the teacher, but not to the Vice President. Also worth noting is inequality in power status as exemplified through the use of acceptance in Ellen's talk with 
the Vice President (11.43\%) while none $(0 \%)$ is used with her talk with the teacher. There are not much difference regarding other responding functions such as compliance, acknowledgement, disclaimer, answer, and contradiction. It can be concluded from this study that it is not a problem to ask questions to social figures with higher power status using Interrogative mood types. Consequently, there are fewer chances to share information with high power status than with low power status interactants in an exchange setting. However, fewer Commands and more acceptance features of the service offer are used for interacting with high power status interlocutors.

\section{References}

Adinoto, T. K. (2012). Mood Analysis on Interview Between Oprah Winfrey and Ricky Martin on the Oprah Winfrey Show, Dated On January 24 (Doctoral Dissertation, Dian Nuswantoro University).

Eggins, Suzanne. (2004). An Introduction to Systemic Functional Linguistics. London. Pinter Publisher, Ltd. 2nd Edition

Fairclough, N. (2001). Language and power. Pearson Education.

Fikri, Z., Padmadewi, N. N., \& Suarnajaya, I. W. (2014). Mood Structure analysis of teacher Talk in EFL Classroom: A Discourse Study Based on Systemic Functional Linguistic Theory. Jurnal Pendidikan Bahasa Inggris Indonesia, 2(1).

Halliday, M A K \& Matthiessen Christian M.I.M, 2004. An Introduction to Functional Grammar. 3rdEdition. Arnold Publisher.

Halliday, M A K. (1985). An introduction to Functional Grammar. London. Edward Arnold (Publishers) Ltd.

Nga, N. T. (2017). Doctor-Patient Power Relation: A Systemic Functional Analysis of a DoctorPatient Consultation. Vnu Journal of Foreign Studies, 33(3).

Noor, M., Ali, M., Muhabat, F., \& Kazemian, B. (2015). Systemic functional linguistics mood analysis of the last address of the holy prophet (pbuh). International Journal of Language and Linguistics. Special Issue: Critical Discourse Analysis, Rhetoric, and Grammatical Metaphor in Political and Advertisement Discourses, 3(5-1), 1-9.

TheEllenShow. (2015). "Surprise! It's Vice President Joe Biden!" YouTube, YouTube, 26 Jan. 2015, www.youtube.com/watch?v=LTEiibVnRgl.

TheEllenShow. (2019). "Ellen Gives Back to Inspiring Special Education Teacher Jenna Albi." YouTube, YouTube, 3 Jan. 2019, www.youtube.com/watch?v=Uup3EMvDTeo.

Yeibo, E. (2001). A Discourse-Stylistic Analysis of mood structures in selected Poems of Jp Clark-Bekederemo. International journal of humanities and social science, 1(16), 197203. 